\title{
Telenovelas, narcotráfico y conciencia política en Latinoamérica. Perspectivas sobre un problema de estudio*
}

\section{Soap operas, drug trafficking, and political awareness in Latin America. Perspecti- ves on a study problem}

\section{Juan Carlos Sánchez Sierra}

Referencia para citar este artículo: SÁNCHEZ SIERRA, J. C. (2013). "Telenovelas, narcotráfico y conciencia política en Latinoamérica. Perspectivas sobre un problema de estudio”. En Revista Guillermo de Ockham 11(2). pp. 15-33.

\section{Resumen}

Este artículo examina la incidencia de los contenidos televisivos en la formación de un umbral crítico en el público de América Latina a partir del estudio de la influencia de la cultura popular y de los cambios democráticos en la región, para lo cual se abordan los diferentes valores sociales en juego ante la creciente influencia que tienen las telenovelas basadas en el narcotráfico. Formulado como una reflexión apoyada en una amplia discusión bibliográfica, se analiza la erosión que genera la industria televisiva en las pautas pedagógicas necesarias para fortalecer la incipiente democracia de la región. Antes que abordar lo pedagógico, se hace un estudio de las dinámicas de transformación de los emporios televisivos y cómo través de las telenovelas se instauran narrativas y modelos de acción, atravesados por un deseo desmesurado de éxito y reconocimiento social. En este contexto, el prototipo del narcotraficante es afín a los intereses de los emporios que buscan renovar los lenguajes y personajes televisivos en un proceso en el que la teleaudiencia se enfrenta a contenidos de la cultura popular sin las debidas herramientas críticas y marcos morales, lo cual contribuye a perpetuar la violencia y la ilegalidad.

- Fecha de recepción del artículo: 29-06-2013 • Fecha de aceptación: 06-09-2013

JUAN CARLOS SÁNCHEZ SIERRA. Becario posdoctoral del Centro de Investigaciones Interdisciplinarias en Ciencias y Humanidades de la Universidad Nacional Autónoma de México, donde adelantó entre 2011 y 2013 la investigación Imágenes y representaciones de la masculinidad en la cultura popular de izquierdas en México, 1960-1980. Doctor en Pensamiento Social y Político y magíster en Historia Latinoamericana Virginia Tech. Historiador de la Universidad Nacional de Colombia. Docente-investigador, de la Facultad de Economía y Ciencias Sociales de la Universidad de La Salle (Bogotá). Fundador y director de Red Juventud. Coordinador del libro Juventud, nación y movilización politica en América Latina, 1960-2010 (Santiago de Chile, RIL [en prensa]). Correo electrónico: jcarlosssierra@gmail.com

\footnotetext{
* Artículo de revisión y reflexión científica generado para el Seminario Permanente: "Procesos de Democratización”, del Centro de Investigaciones Interdisciplinarias en Ciencias y Humanidades de la Universidad Nacional Autónoma de México (2011-2012). Fue elaborado durante una estancia posdoctoral en este centro de investigación. Agradezco a los miembros de dicho equipo y, en particular, a las profesoras Margarita Favela Gavia y Alba Teresa Estrada. Ellas favorecieron este trabajo con el tenor de su crítica durante el primer ańo de estancia posdoctoral en esa institución. También, al profesor Carlos Flores, del mismo centro, quien luego de un primer escrutinio en grupo, generosamente compartió conmigo su amplio conocimiento sobre el mundo del cine y la televisión en México y América Latina.
} 
Palabras claves: televisión, narcotráfico, industria, cultural, cultura popular, conciencia política, democracia.

\section{Abstract}

This article studies the influence of television programing in the formation of a threshold for critical thinking among Latin American spectators. Based on a revision of the literature on television and popular culture, and the progressive changes towards democracy in the region, the author explores issues that emerge due to a recent growth of drug-trafficking themed soap operas. Proposed as a literature review and discussion, the author analyzes how the television industry erodes pedagogical foundations necessary to galvanize the incipient democracy in the region. Instead of a pedagogical proposal, here is offered an analysis of the dynamic transformation of the television monopolies and how on behalf of soap operas are offered narratives and paradigms of action crossed by features such as an obsession for success and social recognition. There is where the profile of drug traffickers fulfills the thirst for novelties in language, themes and characters in television emporiums. However, the audience of such T.V. programs faces popular culture contents without a critical toolkit necessary to build for themselves moral frames that would lead to question the form how the industry is helping to celebrate and perpetuate violence and illegality.

Keywords: television, drug trafficking, cultural industry, political consciousness, democracy.

La farándula tiene un rol politico, es un instrumento politico. Mientras más estúpida sea la gente, más va a estar contenta con su miserable existencia.

Marcel Claude

\section{Introducción}

A través de una revisión de la bibliografía más destacada sobre televisión en América Latina y en particular en Colombia, este artículo propone líneas de interpretación que corresponden a un proyecto de investigación en el que se contrastan las tendencias de la industria televisiva de los países a partir de 1960, con el fin de comprender la forma como en las telenovelas se promueven narrativas y modelos de heroísmo que inciden en la percepción de los televidentes sobre lo político, la legalidad y la democracia. Esta investigación forma parte de un trabajo más amplio que comenzó durante una estancia posdoctoral, en el que se estudian manifestaciones de la cultura popular en México y Colombia y se intenta esclarecer la relación entre diversas formas de expresión política y la idealización de una variedad de perfiles de masculinidad atravesados por una legitimización de la violencia.

\section{Contextos y conceptos: la cultura popular y los desafíos de la democracia}

La investigación social sobre el fenómeno del narcotráfico y su correlación con la cultura popular merece especial atención a la luz de la creciente influencia que tienen sobre la sociedad civil productos televisivos que inciden en la orientación política de los ciudadanos de cada país ${ }^{1}$. La sociedad contemporánea tiene en la cultura popular una fuente significativa de imágenes que, aunque no sean necesariamente las más apropiadas para su formación, inciden en su visión del mundo y los valores con los que incursiona en el proceso de interacción y reproducción social (Ashby, 2010). Las percepciones políticas que reposan en la cultura popular a menudo se han considerado como deformantes, cuando no simplemente un vehículo para

1. En esta investigación se hace uso de definiciones amplias en el campo de lo teórico, para que de allí se puedan desprender hipótesis y explicaciones de largo alcance, contextualmente situadas. De esta forma se puede cubrir ampliamente la realidad estudiada, un paso necesario con miras a la teorización ulterior desde los casos particulares que se abordan en la investigación. A manera de una definición provisional, la cultura popular se considera aquí como un ámbito de producción y consumo de artefactos que se insertan en la dimensión cultural de una sociedad para su reproducción, mediada por los factores que en cada contexto pueden determinar la recepción que un público puede hacer de cada elemento, y en la cual se manifiesta un conflicto social que distingue en términos socioeconómicos y culturales las preferencias y desigualdades del público consumidor. En los niveles de producción y consumo, la cultura popular está determinada por la orientación de su contenido para cumplir una función que se le asigna ya sea por factores circunstanciales o estructurales de las fuerzas sociales y los medios de comunicación, en el que funciona como complemento o substituto de la educación, pero con una premisa en la que la ecuación costo beneficio surge atravesada con un interés por atraer masivamente al público y que la recepción sea positiva y redunde en la validación de aspectos morales inherentes a la industria cultural predominante en cada sociedad estudiada. 
la despolitización de los actores sociales (Canclini, 1982; Thompson, 1998; Barbero, 1999). Esto se debe a que a menudo no concuerdan con determinadas orientaciones ideológicas o son descartadas porque no estimulan la formación de umbrales críticos que permitan discernir entre la ficción, la realidad, parámetros morales constructivos y la equidad o tolerancia deseables para una sociedad democrática. ${ }^{2} \mathrm{La}$ importancia que adquiere la cultura popular en la cimentación de umbrales críticos para la sociedad se debe al escepticismo respecto al beneficio de su penetración cultural y el desestímulo de la formación de sus consumidores (Rodríguez, 1989; Uribe, 1991; Rincón, 2002). Este señalamiento parcialmente denuncia a las elites que controlan los medios de comunicación por sustraer a la población de herramientas que le permitan conocer horizontes más allá de la vida cotidiana, la subsistencia o la marginalidad, profundizando así su enajenación (Ayala y Duque, 2006).

Las democracias latinoamericanas, con una larga historia de debilidades y ambigüedades, son un contexto adecuado para el análisis de la relación entre juventud y cultura popular. La participación política de la juventud en la región ha adquirido importancia desde la década de 1970, vía el sufragio, y más recientemente impulsando movimientos sociales que permiten algunas transiciones democráticas. Sin embargo, subyace una ambigüedad en cuanto los jóvenes no son considerados como parte central en la vida política. De un lado, por la herencia de una visión paternalista y condescendiente que predomina sobre su participación; de otro, porque predomina una subestimación del sufragio como el campo en el que la juventud puede impulsar cambios sociales de importancia (Sánchez y Torres, 2013).

Los procesos descritos vienen mutando desde la década de 1980, cuando las democracias de la región comenzaron a restablecer por la vía de la legitimidad de sus constituciones la consolidación de un tejido social incluyente. Aunque la participación juvenil en política fue atada a toda suerte de condicionantes bajo el argumento de la necesaria maduración y despertar de la conciencia -allí la educación cívica debería jugar el papel de resolver inquietudes y expectativas de los jóvenes-, los productos que fueron diseñados para cautivar su atención fueron contenidos que en la cultura popular han brillado por su opacidad crítica. Estas visiones de la juventud en política, fomentadas por el el Estado y los emporios económicos y que dictan la ruta de la cultura popular, presentan fallas que impiden a las nuevas generaciones sintonizarse con lo político, pues ocultan o disfrazan la realidad social (Morales, 1990; Restrepo, 1990). La incidencia de estas percepciones sobre la cultura popular y la educación en una conciencia crítica, ha despertado el interés de investigadores que aluden problemas en el papel jugado por los medios (Rincón, 2002) y fallas que atraviesan la estructura educativa de Colombia y en general de América Latina (Pereira, 2001; Rodríguez, 2008). Sin embargo, a la hora de abordar aspectos específicos del fenómeno, como los son las telenovelas y su efecto en la juventud o la ciudadanía en general, tanto la participación democrática como la categoría de juventud resultan afectadas por una visión condescendiente respecto a la juventud que aun comparten los académicos (Quintero, 2002) y que a menudo -y con algo de inocencia- sobredimensiona el posible papel del

2. Estudiada en ámbitos sociohistóricos en los cuales la fragmentación ocasionada por la convivencia de lo moderno y lo tradicional, los variados artefactos de la cultura popular promueven la formación de narrativas que explican un amplio espectro de la realidad social y la experiencia individual. Estas narrativas forjan y transforman constantemente las representaciones que en la sociedad constituyen visiones del mundo, o imaginarios funcionales en la ubicación política de los actores. Aquí se usa una definición discreta de las representaciones, concebidas como construcciones de sentido que asignan un color político e ideológico a la realidad a través de conceptualizaciones gestadas por el individuo en su interacción social. Las representaciones están mediadas ideológicamente, por lo que metodológicamente deben estudiarse desde una plataforma crítica. Cuando esas representaciones determinan la apropiación de la realidad y su experiencia vivencial, constituyen el tejido de imaginarios cuya función es dar sentido al mundo por la vía de narrativas. Estas definiciones atienden la necesidad de evitar la difusa comprensión que puede darse desde una visión del mundo político como ideología, y la acción social como su producto residual. En particular, y bajo la forma de narrativas —en general alimentadas cíclicamente por los productos de la misma cultura popular-, permiten en el púbico/espectadores una recepción en la que se manifiestan tanto las expectativas colectivas e individuales, como las formas que adopta la subjetividad en contextos de dinámico cambio social. Para un acercamiento a esta perspectiva de análisis, (ver Joseph, 2001). Un caso de estudio comparativo en América Latina similar, fue el de las disputas ideológicas propias de la Guerra Fría, y allí las narrativas sobre el desarrollo, la revolución y el progreso, en las que los sectores políticos de México, Guatemala y Cuba alimentaron narrativas divulgadas por la cultura popular y avaladas por los respectivos regímenes políticos de cada nación (ver Saldaña-Portillo, 2003; McCaughan, 1999). Allí, la narrativa del cambio social puede considerarse como análoga a las que promueve la cultura popular sobre la movilidad social y la porosidad de la moralidad de las actividades del narcotráfico. 
Estado en la garantía de ese acondicionamiento de la sociedad para forjar una población que podría revestir un peligro al cuestionar su legitimidad (Pérez y Rojas, 2009).

En este artículo se propone una aproximación que no atribuya el peso de una solución a las instituciones, no redunde en la subordinación a los jóvenes y ciudadanos desde lógicas dominantes de conocimiento y que en su lugar pondere la forma como los medios se fortalecen en la ignorancia de sus consumidores. Mientras la mentalidad vigente persista en definir la trayectoria de los contenidos televisivos bajo lógicas económicas, poca esperanza podemos depositar en la expansión de la democracia y el cuestionamiento a fondo de la crisis social que puede ocasionar su desviación. Por esto, aquí se busca dar continuidad al planteamiento conceptual de Betancourt (1998) al analizar las redes mafiosas en el contexto regional del Valle del Cauca, que puede ser visto no tanto en su dimensión regional como en la parte de las construcciones identitarias. Según el autor, la identidad cultural se advierte en un mecanismo de autopercepción basado en dinámicas de reconocimientos, cuyos referentes son adoptados de la experiencia vivida y percibida. Para Betancourt, la experiencia consiste en una serie de "representaciones simbólicas, valores, actitudes, opiniones, habitualmente fragmentarias" en las que se forja "la forma más temprana de conciencia de grupo". Por ello, la identidad es construida o apropiada a partir de "imágenes, símbolos, discursos y distintas mediaciones que recibimos en la infancia, en la casa, en el pueblo, en el barrio, con la moda, los trajes las costumbres, las tradiciones, en la escuela, en los periódicos; en una palabra, en todos los distintos mecanismos de comunicación" (Betancourt, 1998, pp. 33-38). El autor decantó su ambiciosa investigación en favor de comprender los rasgos estructurales de las dinámicas regionales del mundo de las mafias y sus actores centrales y dejó para etapas posteriores de su itinerario de pesquisa -que la aciaga violencia del país truncó-los fenómenos de la comunicación y los puntos de cruce entre los estados emocionales y la construcción de umbrales de conciencia -allí el autor sigue a François Dubet, Emile Durkheim y las teorías de Edward Thompson- en lo que llama la "subjetividad personal". En este artículo señalamos cómo los contenidos de la cultura popular y en particular de las telenovelas, inciden tanto en la experiencia individual y colectiva, como en la inserción en la vida política por la vía de una democracia que se supone en expansión y perfeccionamiento.

En la actualidad sigue vigente una visión negativa de la cultura popular, en cuanto perpetúa la ignorancia popular. En lugar de educar, la cultura popular coarta la capacidad crítica de la población al limitar la posibilidad individual de cuestionarse acerca de problemas sociales porque se los considera abstractos y ajenos al ciudadano común (Fuenzalida, 1994). En ese marco de análisis, sus productos antes de cultivar a la población, erosionan derroteros cognitivos que deberían estimular la intriga por la función de los contenidos presentados en los medios masivos de comunicación (Ramírez, 2004; Pérez y Rojas, 2009). De otra parte, para la juventud que consume estos productos es cada vez menos satisfactorio poseer conocimiento o desarrollar capacidades reflexivas que la obligue a asumir posiciones críticas. En su lugar, el estímulo por la vía de la cultura popular televisada estimula reacciones de desafecto social y ocasiona conflictos; por ejemplo, en el impacto del bullying o matoneo en escuelas y universidades (Fuenzalida, 1997; Rey y Bonilla, 2003). Este fenómeno es en cierta medida resultado de la obsesión occidental por mantener separadas las ideas de las emociones (Oathley, 2008), un factor por el cual la juventud termina por evocar lo político como explosión emotiva y por lo tanto, favorecer en ella lo efímero cuando no lo fútil (Riaño, 2006). ${ }^{3}$

Esperar un cambio en los contenidos de la cultura popular sería buscar, en últimas, una modificación en la estrategia de compañías multinacionales para las que maximizar beneficios mediante el abaratamiento de costos es la regla y eso es improbable. Igualmente, la responsabilidad social es cada vez más un asunto ajeno para el Estado, en cuanto se lo atribuye a los actores privados de la economía. Antes que pedirle peras al olmo, es

3. En Latinoamérica se reproduce el modelo de distinción juvenil de los Estados Unidos, con la resultante de una población despolitizada. Lo interesante es que estas predisposiciones juveniles tienden a favorecer el ascenso social fácil, el recurso a la violencia física o simbólica, y visiones estereotipadas de la sociedad, factores estos que amenazan el florecimiento de una esfera pública siempre dependiente del umbral crítico de los ciudadanos. 
necesario reconocer que si no hay estímulos para la inserción del público en debates que cuestionen el orden social, difícilmente se puede aspirar a un cambio favorable en los sistemas políticos y sociales. Un ejemplo fehaciente de este proceso se encuentra en el efecto que vienen teniendo programas televisivos, los cuales proyectan al público percepciones sobre el narcotráfico o la cultura de lo ilegal que antes de promover una concientización de su impacto sobre la historia reciente, impulsan precisamente la reproducción de sus actitudes mientras se establece el desdén por adquirir una conciencia crítica frente a lo político.

El propósito de este artículo es, entonces, recabar elementos para indagar la manera como en la televisión se aborda, legitima y recrea el problema del narcotráfico. Sin elaborar plataformas de opinión o discusión en las que se denuncie la forma como el tráfico ilegal erosiona las instituciones democráticas, se perpetúa la tendencia de desorientar las opiniones y percepciones críticas que se puedan formar los televidentes - particularmente los jóvenes, aunque esta será una variable discreta en el análisis- frente al accionar de grupos violentos o personajes insertos en el tráfico de estupefacientes.

\section{La industria televisiva y el declinar de la pedagogía para la democracia}

La influencia de la televisión sobre los elementos de la cultura popular se ha venido demostrando desde la década de 1960 cuando su uso se masificó de acuerdo con las pautas de consumo que imponían los Estados Unidos y Europa occidental. En esa misma década y tal como había sucedido con el cine y la radio en la primera mitad del siglo XX, la industria televisiva encontró un ajuste ideal con los propósitos de la expansión comercial que buscaba elevar el consumo como indicador de bienestar. Esto contrasta en la relación de la televisión con lo educativo, que además de no ser inmediata estuvo marcada por el hecho de ser considerada un medio para impulsar el consumo antes que una toma de conciencia social. Un acercamiento al tratamiento investigativo que se ha dado al asunto de la televisión como mecanismo de la cultura popular en América Latina, permite reconocer cómo esta fue usada para inculcar representaciones del mundo que desincentivan la formación de una conciencia crítica (Domínguez, 1985; Flórez, 1998; Moreno y Villegas, 1999; Rincón, 2002).

Comprender el papel jugado por la industria televisiva en la desestimación de la crítica en lugar de promover en las telenovelas una percepción política del mundo por medio del ejercicio de incentivar la acción ciudadana, implica identificar las etapas de la industria y los marcos narrativos como vehículos de representaciones sociales (Fuenzalida, 1994; Fuenzalida, 1997). En el estudio de las telenovelas como parte de la cultura popular, sus primeros antecedentes remiten a la innovadora visión de los estudios culturales en la Escuela de Birmingham y otros estudiosos del tema que los tomaron como inspiración (Hall, 1980; Allen, 1985; Browm, 1994; Allen 1995). En ellos predominó una perspectiva crítica frente a la industria y su modo de operación ya fuera por su ímpetu para dominar el ámbito doméstico o por la instrumentalización que hacían actores privados y públicos para usar este vehículo para la difusión de propaganda política, social o de consumo de bienes y servicios acorde con la tónica de la búsqueda de reconocimiento (Thompson, 1998, Bielby y Harrington, 2008).

El impacto de los estudios culturales de vertiente británica fue sentido en Norteamérica a lo largo de la década de 1990 hasta el 2005 cuando se dio su declive en virtud de un agotamiento de temáticas y el viraje de la atención investigativa hacia otros frentes de investigación (Ashby, 2010). A partir de esta influencia en Latinoamérica se dieron trabajos teóricos y empíricos enfocados hacia el análisis del impacto de las telenovelas en las temáticas atendidas por los medios de comunicación y de la televisión como artefacto dominante en la cultura popular (Mazioni, 1993; Covarrubias, 1994; Bisbal y Orozco, 1996). En esta tendencia, parte de los trabajos más representativos buscaban identificar la relación entre la desactivación política de los actores sociales en el contexto de la globalización y el creciente consumo de productos televisivos, en la cual se proyectaban estilos de vida marginalizados o que, de plano, reivindicaban la ilegalidad (Martin Barbero y Muñoz 1992; Martin-Barbero, 1993; González, 1998). Sin embargo, fenómenos como el narcotráfico aún no ocupaban el centro de atención en cuanto predominaban historias de arrabal, marginación rural e imágenes idealizadas de las aspiraciones populares urbanas 
en procura de senderos para agilizar su acceso a la tierra prometida del ascenso social. Estas temáticas descollarían entre finales de la década de 1990 y a todo lo largo de la primera del siglo XXI (Rodríguez, 2008; Valderrama, 2009).

Para el caso colombiano, los estudios de la cultura popular se rezagaron en buena medida por el carácter predominante de los estudios sobre la época de la violencia liberal-conservadora y el conflicto armado, que se afianzaron en las ciencias sociales en las décadas de 1980 y 1990 (Martin-Barbero, 1997). La correlación entre la cultura popular, las narrativas de las telenovelas y el conflicto armado, solo sería atendida en los años 1990 cuando empezó progresivamente a ser mirada bajo la lupa de los investigadores (Uribe, 1991; Restrepo, 1990; Morales, 1990). Más recientemente, los debates sobre la televisión evocan tres aspectos de interés que vale la pena mencionar. En primer lugar, el hecho de que en las últimas décadas la creciente oferta televisiva coincida con el abaratamiento de productos foráneos -culturales y materiales-; segundo, el incremento en el número de aparatos receptores en los hogares incluidos los más humildes; y finalmente, un declinar irreversible del carácter educativo de los contenidos que allí se transmiten (Thompson, 1998; Valderrama, 2009).

Los aspectos referidos ofrecen una radiografía parcial de la relación entre la industria televisiva y la orientación que la programación ofrecida a los televidentes. El panorama se hace aún más complejo si incluimos variables difíciles de medir como son aquellas que podrían arrojar luz sobre el fenómeno de la recepción social de elementos de la cultura popular y la forma como puede incidir en la interacción social a través de las narrativas allí divulgadas (Rodríguez, 1989). Por ejemplo, la naturalización de las tendencias proyectadas en televisión como positivas; la obsesión generalizada de la población por el reconocimiento en sus ámbitos de sociabilidad; el reconocimiento social basado en lo que proyecta la cultura popular y, finalmente, el seguimiento acrítico de las pautas señaladas en los programas. Todas ellas facetas por explorar por parte de la investigación social que ya comenzaban a denunciarse a mediados de 1980 (Montoya y
Medina, 1986). Si bien algunos trabajos abordan el problema de lo educativo y su incidencia en la formación de una ciudadanía para la democracia (Rincón, 2002; Rodríguez, 2008), esta vertiente apenas detectó de manera tangencial los efectos del fenómeno del narcotráfico en el comportamiento juvenil. Ello indica la necesidad de llevar a cabo un escrutinio de las narrativas proyectadas en la televisión, la forma como la industria ha respondido al envejecimiento de aquellas formas de contar historias heredades de los primeros embriones de los emporios televisivos y la manera como estos se fueron articulando a las lógicas de consumo para forjar paradigmas de acción que determinarían las expectativas sociales y la respuesta social a la cultura popular televisiva.

El desmesurado crecimiento de los monopolios televisivos a la luz de tendencias globales hacia la homogenización de la información también ha merecido un tratamiento investigativo (Elasmar, 2002). Este autor argumenta que la crisis de la educación y la familia ha generado un cambio de paradigma en la difusión de programas televisivos que más allá de las fronteras nacionales promueve pautas de consumo y un reconocimiento social homogéneo que han coincidido con la idea de multiculturalidad. ${ }^{4}$ La neutralización de identidades nacionales que pudieran generar rechazo se evidencia en el uso que presentadores de la televisión hacen de un lenguaje sin trazas de acento o en el predominio del doblaje de películas por casas productoras de México y Argentina que impusieron un modelo de neutralización idiomática de las variaciones lingüísticas nacionales más evidentes. Esta tendencia se posibilitó en el circuito televisivo a partir de la década de 1980 con la entrada del video como una tecnología que abarató los costos de producción y difusión para los canales privados y públicos, factor que favoreció la concentración de casas productoras y de doblaje y edición en aquellos países que desde mediados de siglo contaban con una capacidad instalada para tal fin (X Festival del NCLA, 1989; Kim, 2003). El fenómeno de la neutralización de los acentos nacionales en Latinoamérica fue evidente primero en programas culturales que cruzaron fronteras y marcaron generaciones en

4. Entre las contribuciones al tema destaca un acercamiento más cuidadoso a los intereses entretejidos alrededor de los monopolios mediáticos de comunicación (Jenkins, 2006; Rose y Edgerton, 2005). 
los años 1980 y 1990 y que luego influyó en los diálogos de telenovelas, noticieros y programas populares, para mutar definitivamente en la masiva internacionalización de las carreras artísticas de actores, guionistas y directores de televisión que a finales del siglo XX tenían un estilo de hablar y entretener copiado -cuando no confeccionado- de manera acrítica e impune de los Estados Unidos (Singhal, 2003).

Aunque la televisión y la sociedad se reflejan mutuamente en las telenovelas, ese doble espejismo se reafirma a través de imágenes alteradas de lo social alimentadas por estereotipos o paradigmas individuales creados muchas veces arbitrariamente y alejados de cualquier racionalización crítica de los problemas sociales (Herrán, 1991). En la cacofonía de productos de la cultura popular, la industria televisiva viene construyendo desde los ańos 1980 narrativas que si bien no innovan en términos del lenguaje sí promueven marcos de comprensión a través de modelos ficcionales que tienen un profundo calado en los televidentes. ${ }^{5}$ Fenómenos como el racismo, la subordinación, la distinción socioeconómica o el desbalance en las relaciones entre los sexos perviven en la televisión. Allí se fomentan marcos mentales y morales que definen la interacción social y es la industria la encargada de difundir las redundancias en las que cayó pronto el lenguaje y las moralejas de las telenovelas.

El hecho de que sean tipologías y no realidades las que subsisten en la televisión, hace que se la asocie con una "caja mágica" como un artefacto ilusorio pletórico en narrativas sobre la realidad y se haga de ella un medio de distracción antes que un formador de pautas y enseñanzas (Montoya y Medina, 1986; Rey, 1998). Esta consideración de la televisión como ajena a una función formadora permite que los programas presentados sean vistos como neutrales (sino inofensivos). Empero, se trata de una inocencia falsa dado que los elementos vistos en la televisión se convierten rápidamente en marcadores de estatus y en símbolos de pertenencia a la sociedad de consumo reconocida en general como válida, ineludible y venerable (Hernández, 2003).

\section{Novelas e industria televisiva en América Latina, notas para un balance}

Durante la Segunda Guerra Mundial la industria cultural mexicana no solo propagó los preceptos impuestos según las necesidades occidentales a todo lo largo de la región, sino también los estilos, estereotipos y narrativas propias de su concepción del género policial y las formas de asimilación del hito de la revolución mexicana como amenaza a la seguridad e integridad del sueño americano (Mora, 1982; Romo, 1991). Esta percepción, gracias al desarrollo de estrategias comerciales de distribución facilitadas por el emporio fílmico de México y dada la afinidad cultural y de la lengua, convirtió a este país en irradiador y distribuidor de una idea estereotipada del ser latinoamericano llevado al cine y la televisión, una tendencia que luego pasó al contexto venezolano donde el lenguaje de las telenovelas se fue modificando según las necesidades regionales de la cultura popular. En México el género policiaco constituyó una marca particular de la duradera tradición de radionovelas y luego de las telenovelas en las que el estilo de vida rural ha corrido paralelo a la estética de la marginalidad e ilegalidad (Romo, 1991; Merayo, 2007).

Las narrativas, entre tanto, corrieron de la mano de la idealización de revolución mexicana, proceso que sirvió de referente de lo rural como barbarie, de la oposición entre el bien y el mal y como agente de unificación de los marcos morales que se accionaron en la reactivación de oposiciones y conflictos allí cristalizados. Terratenientes y villanos intercambiaban papeles en melodramas como portadores del deseo, el odio, la verdad y la mentira y se convirtieron en dogmas sociales necesarios para estereotipar a las masas consumidoras que observaban impávidas los productos de los emporios televisivos. En ese intercambio de roles impusieron el estereotipo del latinoamericano como síntesis de la pasión que siempre perturbaba la ley y la moral pese a la rigidez social. Fue así como se marcaron pautas que perduraron durante décadas en la región, instrumentalizadas por la industria televisiva norteamericana para la reproducción en cada contexto nacional.

5. Para una lectura al tipo de modernidad que los medios buscan promover a partir del carácter narrativo de los géneros televisivos y el impacto sentimental que tienen en los televidentes, ver Hellinghaus (2002). 
Esta percepción de lo mexicano como lo retrasado es homóloga a las historias que del otro lado de la frontera difundían ejemplos de subordinación, degradación racial, distinción socioeconómica y desprecio cultural que en últimas exaltaban los valores estadounidenses presentados en aséptica oposición a los ámbitos deseables y despreciables de la colonización de la cultura popular norteamericana (Kimmel, 1996). Lo que se inició en la radio, pasó en 1940 al cine (Mora, 1982) y luego a la televisión (Orozco y Bisbal, 2007). Estos géneros se hibridaron para dejar una marca profunda en la cultura popular contemporánea y sobre todo en Latinoamérica, la casa matriz de las principales innovaciones y repeticiones en el género de las telenovelas (Merayo, 2007). La televisión instaló este en la cúspide de la producción cultural de los medios masivos en un proceso que se inició en la década de 1960. Si bien México mantuvo la delantera en el género y lo reprodujo hasta la saciedad (Martín-Barbero, 1992), la crisis económica de 1970 coincidió con un auge de la industria televisiva (Covarrubias, 1994) que se alimentó de las dificultades de la industria cinematográfica para renovar su lenguaje y sus temas y que tuvo en la televisión una salida deshonrosa pero económicamente gratificante (González, 1998). A pesar de la crisis del cine y de la falta de un espíritu propio en el lenguaje televisivo, en México -como en todo el mundo- la televisión se convertiría en el refugio del entretenimiento popular, razón por la cual las cicatrices culturales creadas por los estereotipos y las distinciones económicas, raciales y culturales no sanaron, sino que, por el contrario, tendieron a deformar percepciones sociales e individuales que anestesiaron la demanda por una sociedad más equitativa o por una democracia que sobrepasara lo formal y fuera más bien funcional (Navarro, 2003).

Los sobresaltos económicos transfirieron las experiencias y la estrategia a los lugares donde los caudales brotaban. Si los años sesenta fueron una década perdida para la industria cinematográfica mexicana en contraste con el auge de la televisión, la década de 1970 fue una debacle económica que minó los logros del modelo del desarrollo estabilizador. Dicha crisis abrió un espacio en otros países de la región para que la industria televisiva creciera con tecnologías relativamente modernas y con casas productoras que educaban una masa consumidora acrítica (Fuenzalida, 1997). En la reproducción industrial de formatos de telenove- la, el turno en la rayuela fue para Venezuela que funcionó como otro ejemplo sin parangón en los años aciagos de la crisis energética. En 1980 este país ocupaba el lugar de honor en la producción de telenovelas con propuestas populares y que auguraban renovaciones marginales pero ganancias sustanciosas en el género (Rondón, 2006). De esta manera, la lógica económica de maximizar beneficios minimizando costos se impuso en la televisión latinoamericana.

Como en México, en Venezuela las novelas empezaban a jugar con facetas históricas y narrativas de corte urbano o rural o con particularidades hogareñas de los antagonismos de sexo e intergeneracionales. Los conflictos sociales y la desigualdad servían para nutrir los relatos que instruirían al público en formas de sociabilidad acordes con las distinciones socioeconómicas, geográficas y culturales del país (Acosta-Alzuru, 2002). Venezuela se convertiría en el motor de la industria televisiva en Suramérica durante más de una década y en modelo de un estilo de vida basado en la abundancia económica y en el despliegue de los símbolos distintivos de éxito que incluían el derroche en el lujo y el desprecio por las condiciones culturales de los sectores populares o campesinos. Venezuela era una nueva tierra prometida en materia televisiva y fue allí donde se estimularon combinaciones estéticas que reflejaban la aspiración de las élites del país por hacer de Caracas un ejemplo de desarrollo y tropicalismo paradisiaco equiparable a Miami que desde finales de la década de 1970 sirvió de referente sobre lo que significaba el sueño americano en su versión caribeña (Espada, 2004).

El periodo de 1980, significó asimismo un progresivo despegue de agentes privados que impulsaron el género mediante inyecciones de capital orientado a mejorar la tecnología y la cobertura así como el tipo de programación a través de canales en su mayoría estatales, pero manejados por intereses privados. La transición tecnológica significó un cambio en la orientación de los contenidos televisivos que buscaba reducir costos y adoctrinar a los televidentes gracias a una lógica mercantil que permitía poco espacio a la elaboración temática o la pedagogía (Rondón, 2006). Los programas culturales y educativos quedaron marginados a horarios poco atractivos o terminaron sus días en canales cuya capacidad tecnológica declinaba ante la pobre rentabilidad que representaban para los 
interesados en contratar pauta comercial. El consumo televisivo crecería en adelante desligado de una tarea educativa y más bien obedecería a las lógicas de la reproducción de capital merced a la explotación de licencias, a esquemas de programación y a un desinterés de los Estados en toda la región por regular los contenidos televisivos. A finales de 1980, la lógica comercial estaría destinada a servir los intereses que internacionalmente imponían los sistemas económicos liberalizados a través de ajustes estructurales que reducían las funciones del Estado en la economía, y desmontaban barreras gubernamentales sobre los contenidos proyectados en la "caja mágica".

En este contexto, durante la segunda mitad de la década de 1980 sería Brasil el principal ejemplo de asimilación y expansión del modelo televisivo que México y Venezuela promovieron durante sus años de auge económico (Fadul, 1993). Elementos culturales como la diversidad del subcontinente brasilero serían explotados en una folclorización de las tensiones raciales y económicas por la vía de una estigmatización en el uso del lenguaje, los deportes o simplemente pautas de consumo (Mattelart y Mattelart, 1990). Como señaló otro autor en un trabajo de corte antropológico, en Brasil la perpetuación de la brecha entre lo urbano y lo rural se constituyó en una estrategia para cimentar tensiones sociorraciales por la vía de la cultura popular y específicamente la producción de programas televisivos en los cuales se estimulaba en la población el imaginario de la reivindicación social, la redención familiar, el ascenso individual en la retórica del viaje a la ciudad o la parábola del retorno a las raíces y la lealtad con tradiciones y un lugar social predefinido en el azar del destino (Lapastina, 1999). Si bien la televisión no estimuló una trashumancia de las urbes hacia el campo sino más bien lo contrario, en el fondo las telenovelas fomentaban imaginarios para que las capas sociales económicamente más desfavorecidas se insertaran en la vida pública orientadas por el conformismo no a través de acciones políticas, sino siguiendo tendencias en el consumo de bienes y servicios. Como señalaba Nogueira, esto fue particularmente evidente en el errante ámbito rural y semiurbano cuyas dinámicas de mercado local eran difíciles de quebrantar en favor de economías de mercado internacional (Nogueira, 2012).
Estudios recientes han señalado cómo en Brasil se forjaron estereotipos sobre el papel de la mujer en la vida social del país, estigmatizando de esta manera cualquier intento de emancipación del circuito hogar-factoría-hogar; o en el contexto rural, de la fuga de formas subsistentes de sujeción en las haciendas o la labor doméstica de las periferias urbanas (Beljuli, 2011). Estos procesos ocurrieron sin que los encargados del negocio televisivo adoptaran una actitud de responsabilidad social en su actividad, mientras demandaban de los gobiernos de turno mayor autonomía (Nogueira, 2012). En Brasil se impulsaron asimismo transiciones tecnológicas que hicieron del país un exportador de productos e innovaron los medios usados para crear programas (Machado, 2007; Nogueira, 2012). Esto determinó que la industria televisiva en ese país se expandiera y proyectara en la región como un ejemplo del modelo corporativo ideal para adelgazar la influencia gubernamental en los medios de información masiva y de entretenimiento. Sin embargo, el intercambio cultural no trascendió la barrera idiomática y tanto Latinoamérica como Brasil siguieron dándose la espalda mutuamente. Uno de los efectos más importantes de esta lógica corporativa se empezaría a reconocer a finales de la década de 1980 cuando el narcotráfico desbordó los ya difíciles problemas urbanos de Brasil. Mientras se imponían discursos que recalcaban la marginalidad como sinónimo de violencia, pandillas y exclusión, se tenía en la favela y el ámbito rural el caldo de cultivo para una retórica que imponía a los pobres como eternos subordinados (Fadul, 1990), a la mujer como artefacto de uso y cambio a través de la cosificación de su sexualidad y existencia -por ejemplo en concursos de belleza-, la erotización de las tradiciones culturales -en general homogeneizadas en la síntesis de las culturas de Europa, África y América en el Carnaval de Río-, y narrativas en las que se feminizaba la pobreza y se virilizaba al terrateniente $o$ al profesional urbano exitoso (Porto, 2012).

\section{Nuevos temas, nuevos actores: las telenovelas sobre el narcotráfico}

Desde finales de los años 1980, cuando numerosos países de América Latina experimentaron cierto giro hacia la democracia y renovaron sus pactos constitucionales, los medios de comunica- 
ción ganaron un papel central en el aseguramiento de la perdurabilidad del cambio hacia regímenes políticos menos autoritarios. Sin embargo, este propósito no superó la etapa de la enunciación, y más bien se convirtió en fuente de disputas y alianzas entre las élites locales y emporios internacionales que secuestraron las posibilidades de que la sociedad tuviera en la programación televisiva un instrumento para elevar la conciencia popular y consolidar la incipiente esfera pública que podía empezar florecer con la democracia. Mientras las reformas estructurales aseguraban sociedades cautivas a los ímpetus del mercado, y las elites nacionales transferían el control que les quedaba a los grandes monopolios informáticos que dictaban lo que la televisión y la cultura popular debían transmitir, en los bajos fondos de la economía de lo ilícito medraba el narcotráfico como uno de los actores centrales en la erosión institucional que acompañó tan esperanzadora etapa de la historia reciente de la región.

Durante este período, el contexto colombiano serviría como un nuevo derrotero en la construcción de paradigmas televisivos que elevarían las ganancias de actores e instituciones que en representación de intereses privados tomaron el control de la televisión y de las redes de realización y producción, y aseguraron un dominio monopólico sobre la inversión tecnológica que fuera necesaria para mantener una sociedad cautiva bajo la influencia de sus programaciones y las tendencias de consumo allí dictadas. El narcotráfico fue uno de los fenómenos que le aportó nuevos bríos a la industria televisiva en Suramérica merced a la transnacionalización de los capitales invertidos en canales, redes de comunicación y conglomerados informativos.

En Colombia -como venía sucediendo en las industrias televisivas de México, Venezuela y Brasil-, las temáticas proyectaban en la mayoría de los casos idealizaciones de la vida popular en las que los sentimientos amorosos servían de excusa para canalizar las tensiones de clase entre ricos y pobres (Martín-Barbero y Rey, 1999). Este papel de catarsis pronto devino en pauta de conducta social cuando las narrativas de las telenovelas incorporaron nuevos representantes de la sociedad para escenificar situaciones del medio urbano, la marginalización de los campesinos llegados a las grandes urbes y los anhelos populares por ascender en la escala social (Rodríguez y Téllez, 1989; Martín-Barbero y Muñoz, 1992). Mientras en México y Venezuela la presentación de las clases populares estandarizó el uso de tipos sociales ideales, en Colombia las historias de la violencia fomentaron estilos narrativos que vinieron a florecer en la década de 1990 luego de que el país fuera vapuleado por el narcoterrorismo y las acciones espectaculares de la insurgencia que como en el caso del M-19-se sabría después- fueron financiadas parcialmente por los dineros del narcotráfico. Esa violencia que igualaba a ricos y pobres en sociedad, pero con un telón de fondo moralista y compulsivo en los dictados de insertarse en circuitos de consumo y reconocimiento, proyectaba las distinciones sociales, regionales y culturales estereotipadas por la sociedad colombiana desde el siglo XIX (Rodríguez y Rodríguez, 2006).

Mientras en Brasil subyacía un discurso televisivo que resaltaba la epidermis integrativa en la multiplicidad de "brasiles" silenciando así profundas lógicas de exclusión racial (Fadul, 1990; 1993), en Colombia la televisión perpetuó la exclusión del provinciano como forastero en un mundo de capitalinos y cachacos que idealizaban el prototipo urbano de una Bogotá moderna que solo existía en el imaginario de la clase dirigente (Barón y Valencia, 2001). Estas narrativas han funcionado como pautas de exclusión y segregación de la sociedad blanca que por medio de la política y el poder cultural y económico domina a los sectores subalternos, una discriminación que también se manifiesta en los chistes y gracejos de una cultura popular ensordecedora. Unos contra otros: costeños, indígenas, campesinos, todos fueron afectados por las distinciones que mantenían fracturada a Colombia como unidad nacional. El ideal de la ciudad como polo de desarrollo, promesa de mejora en la calidad de vida y lugar preferencial para cumplir el sueño de obtener riqueza rápidamente o algún tipo de reconocimiento que validara su pertenencia a la sociedad, parecía resquebrajarse en los ańos 1990 por lo menos en las telenovelas, pues se impulsó la presentación de las provincias como lugares exóticos reiteradamente desdibujados en estereotipos excluyentes y tejidos a partir de la construcción de un proyecto nacional poco claro (Narváez, 1999).

El conflicto colombiano -que para 1989 tocaría su punto más álgido-se constituiría en las décadas 
siguientes en el ejemplo de las nuevas narrativas que llenarían los espacios televisivos al punto de constituirse en un modelo por seguir por sus pares en Ecuador, Perú e incluso México, Venezuela y los países del Caribe. Antes que proponer un estilo industrial, las telenovelas colombianas refrescaron un temario que había entrado en crisis desde finales de la década de 1970 que en sus narrativas incluía versiones de idealizaciones románticas, subordinación sociorracial y centralización frente a sus regiones tratadas como frontera incivilizada, amén de la ambición urbana de pertenecer a la clase media que al fin y al cabo era la única existente en las pantallas (Fuenzalida, 1994). La negación de la condición paupérrima de la población contrastaba con programas televisivos que mostraban la vida ideal de las clases medias y altas, mientras reflejaban la lucha de clases no como ideal revolucionario, sino como la más acabada narrativa moral de la tensión entre pobres y ricos, buenos y malos, héroes y villanos.

Además de enquistarse en el conflicto social y en la desigualdad inherente a la cultura popular, estos dualismos vertidos en telenovelas fueron funcionales para impulsar marcos morales instrumentales que servían como fachada en la nivelación de una sociedad violenta y con grandes índices de desequilibrio social. La asignación de un lugar ético a los seres que servían de arquetipo no era otra cosa que una epifanía de los profundos conflictos de la sociedad colombiana, de allí que la inclusión de temas populares en las novelas colombianas en contraste con la ineficacia generalizada a la hora de proyectar modelos de liderazgo y la ausencia de líderes fuertes a lo largo de su historia, puede explicar que el conflicto se manifieste como una regla de la interacción social y el narcotráfico como la ruta más rápida para el ascenso social, pues ese es el substituto del liderazgo ante el cerramiento de los espacios políticos de reconocimiento y participación (Sánchez, 2011). Esto da lugar a elucidar la aparición de modelos de heroísmo -o antihéroes- que se caracterizan por su arrogancia frente a la ley y el recurso constante a la violencia.

Sin embargo, el fenómeno va más allá de la dinámica de la industria televisiva, pues justamente problemas como el recurso a la fuerza y no a la inteligencia, el sometimiento femenino condicionado por aspectos sexuales y la reverencia por estilos de vida violenta e ilegal, tendrían en Colombia un caso legendario en el que facetas normalmente señaladas como negativas se convirtieron en valores exaltados en la pantalla. La televisión solo vendría a corroborar unas pautas aprendidas del modelo norteamericano que en la imaginación colombiana eran llevadas a su expresión más acabada (Rincón, 2002). Los paradigmas modelados en el fragor del narcotráfico hunden sus raíces en las tempranas películas mexicanas: el terrateniente, el guerrillero y el bandolero en sus versiones contemporáneas eran las caras de una misma moneda. De la personificación de héroes y villanos surgió un dualismo que incidió en las narrativas que nutrieron la cultura popular. El auge de estas temáticas se emparenta con el auge del estilo policiaco, la comedia negra y la mistificación de antihéroes inspirados en los años de persecución a las mafias en Italia y Estados Unidos. Sin embargo, el formato por entregas de las novelas llevaba el estilo gansteril a otro nivel dada la amplia penetración del producto ya fuera en la cotidianidad familiar o en la soledad de individuos que anhelaban cumplir con los rasgos épicos del self-made man (Kimmel, 1996).

Los análisis sobre el narcotráfico en Colombia han fallado en presentarnos el valor del liderazgo y su constante resignificación o desconfiguración con la práctica habitual del magnicidio. A la falta de líderes o ante su eliminación sistemática, las narrativas de las telenovelas debían imponer un nuevo prototipo que combinara aspectos promovidos naturalmente por el modelo de la industria televisiva norteamericana desde sus primeros años. Como herramienta de control social, el asesinato de líderes -ya sea públicos o del ámbito privado familiar-ha sido una herramienta útil para disipar los ánimos políticos o manifestaciones de desobediencia. En Colombia, como en otros países de la región, el público termina por reproducir las trayectorias de sus héroes (o antihéroes; depende desde donde se los mire) en busca del ansiado reconocimiento social. En Colombia, el carácter del self-made man mutó progresivamente en un híbrido particular en el que la astucia y la viveza se mezclaban con la violencia, la aversión a la ley y la autoridad y el candor de un humor que arrolla con su personalidad.

De allí que las narrativas románticas y de redención repetidas en todas las formas posibles en las novelas latinoamericanas, hayan tenido en el narcotráfico un soplo reanimador que adiciona 
nuevos elementos y atrapan la atención de los televidentes mientras difunden estilos de vida que se venden en la programación de entretenimiento (Kim, 2003). Pero la inoculación de un estilo de vida por la vía televisiva no tiene reposo, en especial para un público sin alternativas y volcado a la televisión como medio de escape (Sunkel, 2006). Por ello, en el instante de gloria de la industria televisiva colombiana es el "traqueto" el que emerge como paladín social ante la adversidad y aunque no todos los prototipos masculinos de las telenovelas trafican con drogas ni se trata de un núcleo temático omnipresente, lo que surge en el análisis de las novelas exitosas de la última década refleja una sociedad filtrada por esa actitud ante la vida que empezaría a ser reproducida sistemáticamente en las novelas latinoamericanas durante la década del 2000. La expectativa de los creadores, productores, actores y en últimas del público, ha empezado a agolparse en torno a esas temáticas en las cuales el nuevo modelo heroico se siente a gusto, lo cual ocurre sin que existan oposiciones o una voluntad o posibilidades reales de regular contenidos debido a la privatización de la televisión que impera desde finales de los años ochenta.

Esto se evidencia en los temas, las tramas amorosas, las exigencias de voluptuosidad impuestas a las mujeres, el régimen de miedo y violencia que impera en las narrativas, la ambición de lucro y la obsesión por un lujo que se aleja de los parámetros tradicionales forjados con tanto esmero por las telenovelas mexicanas y brasileras. El aroma chabacano que se percibía décadas atrás en las novelas venezolanas se impone y marca parámetros para las nuevas generaciones que observan esas tramas épicas quizá sin detectar lo que hay de fondo; o conscientes de ello carecen de un andamiaje crítico con el cual discernir sus posibles efectos.

El fenómeno puede ejemplificarse al observar el efecto de los contenidos televisivos que aluden al estilo de vida propio del narcotráfico sobre la audiencia. La atención sobre el problema es más bien reciente, pese a que bullen trabajos significativos sobre la influencia de las telenovelas en la sociedad y sobre el impacto del narcotráfico como factor determinante en la vida cotidiana de los colombianos. Sobre esta actividad, quizá la investigación mejor lograda respecto de la cultura que se genera a su alrededor sea el análisis del sistema económico y el tejido simbólico que se da alrededor de las redes intermedias de tráfico y cómo la figura del "traqueto" -que dinamiza la distribución hacia Estados Unidos y Europa- se ha constituido en un paradigma de acción que sintetiza las aspiraciones populares pese a su discreta sujeción a la ley (Betancourt, 1998). Allí, los frágiles modelos de liderazgo que teje la sociedad, terminan por ser suplidos por el narcotráfico, pues ofrecen prototipos de heroísmo alternativos a los que el Estado promueve con su débil legitimidad. Este personaje pasa de la vida real a incrustarse en la cultura popular como un modelo, aunque en los productos televisivos haya iniciado su periplo con un bajo perfil. De allí que como negociante de droga que ocupa el imaginario social constituya un dispositivo de interés para el desciframiento de los cambios en las narrativas de las telenovelas. En este prototipo social se sintetizaban el estilo de vida ostentoso de los Estados Unidos y la concepción de la movilidad social como desligada de una participación en actividades lícitas o por la vía del ejercicio de los deberes y derechos de ciudadano.

El profesor Darío Betancourt, quien murió a manos de la guerra sucia que desató el paramilitarismo como retaliación contra la investigación social, dejó trunca una prometedora contribución analítica enfocada al tejido social y a la forma como el narcotráfico vino a reparar a través de unos nuevos referentes simbólicos, las heridas que desde la violencia liberal-conservadora afectaron el vínculo social mediado por lo político-partidista. El narcotráfico -según presentó Betancourt en su obra- también desestabilizó la economía legal que prosperó por décadas en el Valle del Cauca y zonas aledañas, por lo que desarticuló los vínculos sociales con otros referentes de liderazgo, masculinidad y éxito social.

La investigación de Camacho Guizado (Camacho, 1989; 1991; 1993) ofreció para el debate un estado del arte y una aproximación teórica que sirvieron de antesala a un conjunto de obras publicadas una década después (López-Restrepo y Camacho, 2004). En las obras de 1990, Camacho estableció tipologías útiles para identificar la relación entre los capos del tráfico y la sociedad civil, tanto en el ámbito urbano como rural. Allí el sociólogo propuso un examen a la vida de la juventud urbana en Cali, donde la marginalidad, la falta de educación y oportunidades laborales terminaron por anidar las actividades más extremas que 
requería el narcotráfico para su posicionamiento y sustento, como lo fue el sicariato. Para el caso de la juventud en Medellín, Pilar Riaño ofrecería años después un acercamiento antropológico a la memoria de los participantes en actividades sicariales que asolaron la ciudad durante más de diez años, algo que la autora atribuye a la marginalidad, la falta de empleo y educación y finalmente a la exclusión de la juventud de la vida pública y política colombiana (Riaño, 2006). Aunque estos trabajos que abordan principalmente los efectos del narcotráfico en el tejido social y la juventud no profundizan en aspectos específicos de la cultura popular ni en la influencia de los masivos de comunicación o de géneros específicos como las telenovelas, sino que ofrecen interpretaciones de interés para la comprensión de las barreras que impiden el afianzamiento de instituciones democráticas en Colombia.

Las novelas sobre el narcotráfico trajeron consigo una exaltación de la vida peligrosa y ostentosa que transcurre en la zona gris de la ilegalidad. El problema radica en que la televisión con sus programas de entretenimiento legitimó progresivamente marcos morales cuestionables que subyacían en la voracidad y carencia de marcos éticos del modus operandi de las élites tradicionales; así, la violencia formaba parte de los relatos telenovelescos de la "caja mágica". En las narrativas del cine y la televisión, el héroe y el villano han jugado un papel ambiguo, sea que se lo analice desde la cúspide o la base de la pirámide social. Por ejemplo, no eran los efectos sociales de sus actos, sino los valores domésticos más tradicionales los que salían a flote en la exaltación del terrateniente, el rico o la doncella. $\mathrm{Al}$ no exaltar rebeldes proclives a la insurrección, se hacía dócil el discurso de los subordinados en el que la obediencia, la baja autoestima y el conformismo constituyeron reglas básicas del buen ser de los de abajo. Este fenómeno de desdibujar los paradigmas de liderazgo social marcó pautas de conducta, en parte debido al retroceso del nivel educativo en gran parte de América Latina.

Si bien el florecimiento de este tipo de programas no es nuevo, lo curioso es que coincide con el estrepitoso declinar de productos educativos que pasaron de ser una base en la programación televisiva diaria a convertirse hoy en propuestas alternativas marginadas por el bajo rating y el consiguiente desinterés comercial por estimular- los (Rodríguez, 2008). Si consideramos que la programación cultural fue significativa en décadas pasadas, se puede sugerir que empiezan a padecerse los efectos del vacío dejado por programas que fomentaban una pedagogía para el televidente que sirvió en la formación de pasadas generaciones. En esta ausencia se dilucida el impacto en las nociones juveniles de lo político y lo democrático, pues han dado paso a que la función educadora la tengan ficciones en las que se juega con la realidad y narrativas que refrendan estereotipos o formas de vida asociados con la contravención de la ley antes que con el reconocimiento de los televidentes como ciudadanos activos depositarios de deberes y derechos.

\section{Conclusión: por una televisión para la democracia}

La pedagogía política y democrática -que parecía ser una promesa en las reformas constitucionales de los países latinoamericanos que se insertaron en la democracia participativa desde la segunda mitad de la década de 1980-, resultó una temática postergada en la definición de los actores e instituciones encargadas de la programación televisiva en la región. Las narrativas televisivas figuran como elementos centrales en la configuración de las representaciones de la realidad de la teleaudiencia, razón por la cual al considerar los años 1980 y 1990 es necesario incluir la cuestión de la sensibilidad popular frente a los problemas de violencia y corrosión del tejido social ocasionados por el narcotráfico en cuanto factores que estuvieron en la agenda política de restablecimiento institucional y en el acomodamiento de cada país a las necesidades del mercado, pues los ajustes estructurales venían de la mano con las pautas narrativas con las que la industria televisiva amplió su repertorio de entretenimiento para el público.

Entre los efectos de este proceso se puede incluir la creciente exposición de la población juvenil a temáticas sensibles. Por ejemplo, en Colombia desde comienzos de la década pasada se transmiten telenovelas que abordan el tema del narcotráfico y más recientemente etapas del conflicto armado actual. Estos tópicos son sensibles en virtud de que remueven pasados dolorosos, irresueltos y problemáticos, en cuanto la lógica activa en su 
programación no es una de corte educativo, sino que imperan prerrogativas relativas a los niveles de sintonía. Esto limita la posibilidad del hogar como ámbito pedagógico en materia de valores, lo que lleva a una reconfiguración de los marcos morales con los que evaluamos nuestro lugar en la sociedad (Rincón, 2002) y tiene una incidencia innegable en una democracia, más aun cuando esta es precaria o se encuentra en formación. El problema de fondo estriba, asimismo, en que esas narrativas ficcionales tejen una fragmentaria visión del pasado que el televidente termina por identificar con la realidad, pese a las ambiguas advertencias sobre el carácter híbrido entre pasado y realidad. El ciudadano queda así expuesto a un contenido de origen poco claro sin contar con suficientes elementos de juicio para tomar decisiones y adoptar posturas cuya repercusión pueda ser mensurable; por ejemplo, en tendencias democráticas o cambios en los sistemas políticos (Ramírez, 2004).

Los medios promueven en la juventud la compulsión por el presente (la idea de vivir rápido es un invento del consumo de masas del siglo XX) y la obsesión con el futuro, pero desde la televisión poco se estimulaba una aproximación autónoma a las historias locales. Esto traía como consecuencia que los constantes reacomodamientos de la memoria colectiva-particularmente en países con un pasado atravesado por la violencia y la ilegalidad como ocurre con los países afectados por el narcotráfico- fuera de alguna forma secuestrada por los creadores de tendencias en la cultura popular y particularmente la televisión, el cine y la radio. Esta colisión entre las reconfiguraciones de la memoria resulta ser parte central de la incomprensión que subyace en la llamada "brecha generacional", que impide una comprensión entre jóvenes y adultos y perturba el acomodamiento social en torno a elementos convergentes respecto a la enmienda de fallas del pasado por la vía de la reconciliación. En su lugar, la televisión ha estado allí para sazonar las acres disputas entre jóvenes y adultos, razón por la cual es necesario reconocer que una de las facetas más problemáticas del fenómeno está en el creciente papel que juegan las telenovelas en la formación juvenil.

En este artículo se recalcó cómo para la televisión contemporánea es prioridad maximizar beneficios abaratando costos. El fundamento de este axioma estriba en que incentiva una teleau- diencia interesada en consumir y responder a los beneficios intrínsecos de las narrativas de las telenovelas en las cuales se insiste en el afán por el reconocimiento y el ascenso social acelerado antes que en la formación de un criterio necesario para poseer la idoneidad para el ejercicio de una ciudadanía activa y cuyo resultado es lo opuesto a un público culto forjador de opinión. La mediocridad de contenidos inherente a esta mercantilización de los productos televisivos se justifica en excusas: de una parte, un sometimiento a la política empresarial de canales y productores a la dictadura del cliente; de otra parte, la necesidad de proveer al público de entretenimiento vacuo y fácil de digerir. La primera es la lógica industrial del siglo XX; la segunda, la típica inculpación de la víctima que hace el verdugo.

La lógica de estos argumentos de la industria es, además, circular; como la parábola descrita por la caída de la capacidad crítica del público para discernir entre lo bueno, lo adecuado, lo pernicioso y lo definitivamente contraproducente. Cuidadosa de no relativizar en lo moral, la academia responde a esta lógica tautológica con una posición según la cual un público no puede demandar y degustar aquello que no conoce. Mientras la academia y los medios de comunicación no incorporen en sus umbrales éticos la educación orientada hacia la concientización de la sociedad basada en una realidad concreta y descrita en formas que por discernibles no dejan de ser filosóficas, artísticas o intelectuales, quizá brote una esfera pública condenada a fracasar en la guerra de las distinciones, las disputas de poder y el egoísmo de los campos de interacción.

Asumir que se presenta y realiza lo que el público pide es una forma camuflada de comulgar con la premisa impuesta por la industria televisiva sin increpar la deliberada omisión de las herramientas de juicio para una sociedad imbuida en visiones del mundo en color rosa y sin reconocer las contradicciones en las que nos debatimos como sociedad. La reproducción de modelos ha impedido por décadas la exposición del público a otras formas de comunicación que fomenten su cultura, por lo cual no tienen por qué conocer o exigir cosas nuevas fuera del circuito de producción. Si los medios crean un público pasivo y poco exigente, ningún deseo por explorar nuevos horizontes surgirá de una población absorta en la real dictadura de 
quienes controlan el negocio televisivo y publicitario; menos aun cuando los modelos narrativos reiteran marcos morales y éticos que se ajustan a las necesidades políticas de cada época y habilitan una tensión social que confronta a hombres y mujeres, ricos y pobres, hacendados y campesinos, patrones urbanos y vecindarios miserables. La perpetuación de estas narrativas contenidas en el modelo industrial televisivo incide en la consideración del público sobre una alternativa posible a un mundo estático, segmentado y maniqueo.

En la misma lógica económica, la falta de educación determina que las clases sociales menos favorecidas dediquen su tiempo a mantener una precaria subsistencia. Frente a las pantallas, se adiestra a un público anestesiado, cauto $y$ obediente. El auge de la televisión como espacio educativo converge con la creciente intensidad horaria de las jornadas laborales de padres y madres y el declinar de la educación formal como proveedora de pautas e imágenes constructivas en la formación de la personalidad política de cada individuo. Así, mientras la televisión educa en el consumo, se vienen redefiniendo globalmente las estrategias en campañas electorales, pues hoy la política vende los beneficios de identificarse con un candidato-producto en lugar de contenidos políticos en los que la crítica debería ser primordial. Esto sería maravilloso si los gobernantes elegidos fueran responsables, pero la época no indica esta tendencia ni siquiera en la más optimista de las inspecciones. Si la política va mal, ¿cómo podría la democracia ir bien? Fenómenos como el narcotráfico prosperan en contextos de desorden de los actores sociales y de fragilidad en el tejido que integra sus interdependencias. El hecho de que la televisión haya empezado a incorporar contenidos sobre el narcotráfico obliga a la pregunta sobre la función que puede tener esa cultura popular en medio de una enrarecida atmósfera en la que realidad y ficción aparecen indiscernibles, mientras se exaltan valores que privilegian la violencia y la ostentación de estatus social a partir del acceso a la riqueza rápida sin sanciones sociales o parámetros y valores que sirvan como un armazón en la construcción de una moral social.

En este artículo se ha intentado tejer un análisis de la industria televisiva en América Latina y la forma como cada país ha contribuido desde la orilla fangosa de sus propias tribulaciones. En el género de las telenovelas queda pendiente un examen detallado de los contenidos de las más recientes contribuciones que vulneran la capacidad crítica de la juventud en su trayecto hacia el ejercicio de la democracia, en contextos nacionales donde esa forma de gobierno ha sido extraña cuando no un coto vedado o un sistema tosco y sin dolientes. $\mathrm{Si}$ bien se propone una línea interpretativa a partir de las narrativas y los actores en el acercamiento detallado a los ejemplos más prominentes reposarán respuestas valiosas para discernir las ambigüedades en las que se sume cada país y la región en el unánime trayecto hacia un desbarrancadero. Será necesario, además del examen de sus detalles, la proposición de alternativas que fomenten en la ciudadanía una concientización que se funde en la crítica como una asunto de dignidad y no en la mirada absorta frente a la pantalla, pues en el sillón de nuestras salas o en la comodidad de nuestros dormitorios quizá algún día empiecen las moscas a rondar nuestras cabezas y no será solo por el hedor de seres absortos en su propia decadencia, sino por el aire mortecino que caracteriza la atmósfera de una democracia moribunda.

\section{Bibliografía}

- ACOSTA-ALZURU, Carolina (2007). Venezuela es una telenovela: melodrama, realidad y crisis. Caracas: Editorial Alfa

- ALLEN, Robert (1995). To be continued... soap operas around the world. London: Routledge. (1985). Speaking of soap operas. Chapel Hill: UNC Press.

- ASHBY, LeRoy (2010). The Rising of Popular Culture: A Historiographical Sketch. En OAH Magazine of History 24. pp.11-14.

- AYALA, Germán y SANDOVAL, Oscar (2006). Medios de comunicación y seguridad democrática: de la democracia radical al unanimismo ideológico. Cali: Universidad Autónoma de Occidente. 
- BARÓN, Luis y VALENCIA, Mónica (2001). Medios, audiencias y conflicto armado. Representaciones sociales en comunidades de interpretación y medios informativos. En Controversia, 178. pp. 42-81

- BELJULI BROWN, Lisa (2011). Body Parts on Planet Slum: Women and Telenovelas in Brazil. London: Anthem Press.

- BETANCOURT, Darío (1998). Mediadores, rebuscadores, traquetos y narcos: las organizaciones mafiosas del Valle del Cauca entre la historia, la memoria y el relato, 1890-1997. Bogotá: Ediciones Antropos.

- BROWN, M. E. (1994). Soap operas and women's talk. The pleasure of resistance. London: Sage.

- CAMACHO GUIZADO, Álvaro y CALVANI, Sandro (2007). Narcotráfico: Europa, EEUU, América Latina. Barcelona: Edicions Universitat Barcelona.

- CAMACHO GUIZADO, Álvaro (1991). Cinco tesis para una sociología del narcotráfico en Colombia. En: Revista de la Fundación Foro Nacional por Colombia, 15. pp. 65-73.

- (1993). Narcotráfico y sociedad en Colombia: contribución a un estudio sobre el estado del arte. En: Boletin Socioeconómico, 24. pp. 78-96.

Sociedad, 101. pp. 64-72 (1989). Violencia democracia y democratización en Colombia. En: Nueva

- GARCÍA CANCLINI, Néstor (1982). Las culturas populares en el capitalismo. México: Editorial Nueva Imagen.

- COVARRUBIAS, Karla et al. (1994). Cuéntame en que se quedó. La telenovela como fenómeno social. México: Trillas-Felafacs.

- BIELBY, Denise y HARRINGTON, Lee (2008). Global TV: Exporting Television and Culture in the World Market. Harrington: NYU Press.

- DOMÍNGUEZ, María (1985). Los niños y los medios de comunicación social. Bogotá: ICFES-UIS.

- EDGERTON, Gary y ROSE, Brian (2005) Thinking Outside the Box: A Contemporary Television Genre Reader. Lexington: University Press of Kentucky.

- ELASMAR, Michael G. (2002). The Impact of International Television: A Paradigm Shift. New York: Routledge.

- ESPADA, Carolina (2004). La telenovela en Venezuela (Caracas: Fundación Bigott.

- FADUL, Ana (1993). Serial fiction in tv. The latin American telenovelas. Sao Paulo: USP.

- FADUL, Ana (1990). The Carnival of Images: Brazilian Television Fiction. Westport: Greenwood Publishing Group.

- FLÓREZ, Pamela (1998). Televisión comunitaria: vía de acceso al saber. En: Televisión comunitaria: opción educadora. Bogotá: CNTV-Convenio Andrés Bello-Fundación Social.

- FUENZALIDA, Valerio (1994). La apropiación educativa de la telenovela. Santiago: CPU.

- _ (1997). Televisión y cultura cotidiana. La influencia social de la TV percibida desde la cultura cotidiana de la audiencia. Santiago: CPU.

- GONZÁLEZ, Jorge (1998). La cofradía de las emociones in-terminables: miradas sobre telenovelas en México. Guadalajara: Universidad de Guadalajara.

- GONZÁLEZ, Julián (2004). Repensar el periodismo: Transformaciones y emergencias del periodismo actual. Cali: Universidad del Valle.

- HALL, Stuart (1980). Encodig-decoding in the television discourse. Birmingham CCCS. Paper Series 7. 
- HERLINGHAUS, Hermann (2002). Narraciones anacrónicas de la modernidad: Melodrama e intermedialidad en América Latina. Santiago de Chile: Editorial Cuarto Propio.

- HERNÁNDEZ, José (Ed) (2003). Escuelas, medios alternativos y nuevas tecnologias: una caracterización de las prácticas. Bogotá: IECO.

- HERRÁN, María (1991). La industria de los medios de comunicación en Colombia. Bogotá: FESCOL.

- JENKINS, Henry (2006). Convergence Culture: Where Old and New Media Collide. New York: NYU Press.

- JOSEPH, Gilbert; RUBENSTEIN Anne y ZOLOV, Eric (2001). Fragments of a Golden age. The politics of culture in Mexico since 1940. Durham: Duke University Press.

- KIM, Patricia (2003). Watching from the other side: Latin American telenovelas and latina audiences. Ann Arbor: University of Michigan.

- KIMMEL, Michael (1997). Manhood in America, a cultural history. New York: Free Press.

- LAPASTINA, Antonio (1999). The novela way of knowledge: an etnographic reception study among rural viewers in Brazil. Austin: PhD dissertation, University of Texas at Austin.

- MCCAUGHAN, Edward (1999). Reinventando la revolución. La renovación del discurso de la izquierda en México y Cuba. Siglo XXI.

- MACHADO, Arlindo (2007). Made in Brasil: tres décadas do vídeo brasileiro. Sao Paulo: Editora Iluminuras.

- MARTÍN BARBERO, Jesús y MUÑOZ, Sonia (1992). Televisión y melodrama: géneros y lecturas de la telenovela en Colombia. Bogotá: Tercer Mundo Editores.

- MARTÍN BARBERO, Jesús (1993). Communication, culture and hegemony. From media to mediations. London: Sage.

- _ (1992). Televisión y melodrama. Bogotá: Tercer Mundo.

- MARTÍN BARBERO, Jesús y REY, Germán (1999). Los ejercicios de ver. Hegemonía audiovisual y ficción televisiva. Barcelona: Gedisa.

- MARTÍN BARBERO, Jesús (1997). La Investigación de comunicación en Colombia: balance y prospectiva. Bogotá: Colciencias.

- MATTELART, Michèle y MATTELART, Armand (1990). The Carnival of Images: Brazilian Television Fiction. London: Bergin y Garvey.

- MAZIONI, Nora (1993). El espectáculo de la pasión: las telenovelas latinoamericanas. Buenos Aires: Colihue.

- MERAYO PÉREZ, Arturo (ed) (2007). La Radio en Iberoamérica: Evolución, Diagnóstico, Prospectiva. Sevilla: Comunicación Social.

- MONTOYA, MARTHA y MEDINA, Federico (1986). La telenovela. El milagro del amor. Medellín: Universidad Pontificia Bolivariana.

- MORA, Carl (1982). Mexican Cinema: Reflections of a Society, 1896-1980. Berkeley: University of California Press.

- MORALES, Antonio (1990). ¿Cómo hacen la política los medios y como se comunica la política?. En: Impacto de los medios de comunicación en Colombia. Bogotá: Fundación Konrad Adenauer.

- NARVÁEZ, Ancízar (1999). Participación, comunicación y política ¿De las mediaciones a los medios? En: Bonilla, Jorge y Patiño, Gustavo (eds.) (1999). Comunicación y politica: viejos conflictos, nuevos desafíos. Bogotá: Centro Editorial Javeriano. 
- NAVARRO CASILLAS, Ana María (2003). La interacción entre las familias y la televisión: un estudio en Aguascalientes. Aguascalientes: Universidad Autónoma de Aguascalientes.

- NOGUEIRA JOYCE, Samantha (2012). Brazilian Telenovelas and the Myth of Racial Democracy. Maryland: Lexington Books. (2012). Media Power and Democratization in Brazil: TV Globo and the Dilemmas of Political Accountability. New York: Routledge.

- OATLEY, Keith (2008). Emotions: a brief history. Malden: John Wiley y Sons Publishing.

- OROZCO GÓMEZ, Guillermo Marcelino (1996). Miradas Latinoamericanas a la Televisión. México: Universidad Iberoamericana.

- PORTO, Mauro (2012). Media Power and Democratization in Brazil: TV Globo and the Dilemmas of Political. New York: Routledge.

- PEREIRA, José Miguel (2001). Comunicación y ciudadanía. Apuntes para comprender la radio y televisiones comunitarias. En: Signo y Pensamiento (38).

- PÉREZ, Irma y ROJAS, Hernando (2009). Medios de Comunicación y participación civica. Bogotá: Universidad Externado de Colombia.

- QUINTERO, Fernando (2002). Condición Juvenil y medios de comunicación. En: Nove et vetera (46).

- SALDANA-PORTILLO, María Josefina (2003). The revolutionary imagination in the Americas and the age of development. Durham: Duke University Press.

- RESTREPO, Javier Darío (1990). Los medios de comunicación en Colombia. En: Impacto de los medios de comunicación en Colombia. Bogotá: Fundación Konrad Adenauer.

- RESTREPO, Javier Darío; BARBERO, Jesús y HERRÁN, María Teresa (2003). Guerra y medios de comunicación (Conversatorio). En Revista de Estudios Sociales, 16. pp. 117-119.

- RAMÍREZ, Juana (2004). La mediación de los medios y el bloqueo de la democracia en Colombia. En: Escribania, 13. pp. 13-23.

- REY, Germán (1998). Balsas y medusas. Visibilidad comunicativa y narrativas politicas. Bogotá: FESCOLCerec-Fundación Social.

- REY, Germán y BONILLA, Jorge Iván (2003). Calidad informativa y cubrimiento del conflicto. En: Tamayo, Carlos (coord.) Calidad Informativa y cubrimiento del conflicto estándares de calidad periodística en el cubrimiento del conflicto armado en Colombia. Bogotá: CEREC.

- RIAÑO, Pilar (2006). Jóvenes, memoria y violencia en Medellín. Una antropología del recuerdo y el olvido. Medellín: Universidad de Antioquia/Instituto Colombiano de Antropología e Historia.

- RINCÓN, Omar (ed) (2001). Televisión pública: del consumidor al ciudadano. Bogotá: Andrés Bello.

- _ (2002). La televisión que ven los niños. En: Televisión infantil: voces de los niños y la industria televisiva. Bogotá: Convenio Andrés Bello - Fundación Restrepo Barco.

- RODRÍGUEZ, Clemencia (1989). Historia del melodrama televisivo colombiano. En: Controversia, 155 CINEP. pp. 19-91.

- RODRÍGUEZ, Clemencia y TÉLLEZ, María Patricia (1989). La telenovela en Colombia: mucho más que amor y lágrimas. Bogotá: Centro de Investigación y Educación Popular.

- RODRÍGUEZ, Clemencia (2008). Lo que le vamos quitando a la guerra. Medios ciudadanos en contextos de conflicto armado en Colombia. Bogotá, FESCOL. 
- RODRÍGUEZ, Adriana (2006). La domesticación de la pantalla: historia social de la televisión en Cali (19541970). En: Signo y pensamiento, 48.

- ROMO, Cristina (1991). Ondas, canales y mensajes: un perfil de la radio en México. Guadalajara: ITESO.

- RONDÓN, Alí E. (2006). Medio siglo de besos y querellas: la telenovela nuestra de cada día. Caracas: Editorial Melvin.

- SALDAÑA-PORTILLO, María Josefina (2003). The revolutionary imagination in the Americas and the age of development. Durham: Duke University Press.

- SÁNCHEZ, Juan Carlos y TORRES, Rodrigo (Eds) (2013). Juventud, nación y movilización politica en América Latina, 1960-2010. Santiago de Chile: RIL.

- SÁNCHEZ, Juan Carlos (2011). Worshiping Leadership: Morality, Revolutionary Values, and the politics of Magnicidio (Assassination) in the case of Camilo Torres and Fabio Vasquez with the ELN, Colombia 1963-1978. Blacksburg: PhD Dissertation, Department of Political Science.

- SINGHAL, Arvind; CODY, Michael J.; ROGERS, Everett y SABIDO, Miguel (2003). EntertainmentEducation and Social Change: History, Research, and Practice. Mahwah: Taylor y Francis.

- SUNKEL, Guillermo (2006). El consumo cultural en América Latina: construcción teórica y líneas de investigación. Bogotá: Andres Bello-D’Vinni.

- THOMPSON, John (1998). Los media y la modernidad. Una teoría de los medios de comunicación. Barcelona: Paidós.

- URIBE, Carlos (1991). Democracia y medios de comunicación en Colombia. Bogotá: Foro Nacional.

- VALDERRAMA, Carlos (2009). La investigación en medios de comunicación en Colombia (1980-2009). En: Nómadas, 31. pp. 260-276.

\section{Webgrafía}

- CAMACHO-GUIZADO, Alvaro y LÓPEZ-RESTREPO, Andrés (2004). From smugglers to drug-lords to "traquetos": changes in the colombian illicit drugs organizations. Consultado en Working Paper of the Kellog Fellowship Program, Notre Dame University, 2004 http://nd.edu/-kellogg/faculty/research/pdfs/LopeCama.pdf 